\title{
West Syndrome: How Early is Early for its Presentation?
}

\author{
Shrestha $\mathbf{B}^{1}$, Kiran $\mathrm{K}^{2}$, Ghuliani $\mathbf{R}^{3}$ \\ ${ }^{1}$ Dr. Bikash Shrestha, MBBS, MD, Department \\ of Paediatrics, Nepalese Army Institute of Health \\ Sciences, Kathmandu, Nepal, ${ }^{2}$ Dr. Kamal Kiran, MBBS, \\ MD, Classified Specialist, Department of Paediatrics, \\ Command Hospital, Southern Command, Pune, India. \\ ${ }^{3}$ Dr. Ranjit Ghuliani, MBBS, MD, Senior Advisor and \\ Head of Department, Department of Paediatrics, \\ Command Hospital, Southern Command, Pune, India
}

\section{The Case}

A40 days old male term infant, born by spontaneous vaginal delivery, with no significant risk factors, had presented with complaints of abnormal movements of limbs and eyes. The first episode was noted on day 6 of life which was a sudden jerky movement of all the limbs with upwards rolling of right eye and closure of left eye, lasting for $4-5$ seconds. The movement recurred in succession for 4-5 times. The episode occurred 4-5 times per day, more frequently during early morning hours while waking up. After each episode, the baby used to cry for some time and then used to lay quiet. Subsequently, the movements became more frequent to about 8-10 episodes per day.

On examination: anthropometry and general examination was unremarkable. There were no dysmorphism or neurocutaneous markers. Baby was not showing response to mother or to the environment. Baby did not follow light. There was hypertonia in all the four limbs with bilateral extensor plantars. Baby lifted head up on horizontal suspension. On vertical suspension, the legs were extended but not crossing. All the tendon jerks were exaggerated. Moro's reflex was incomplete. Rest of the systemic examination was normal. The seizures continued and the succession occurred in 7-8 times and 10-15 times each day. Routine blood investigations were all within normal limits, including sugar, calcium and electrolytes. CSF study did not reveal any abnormality. The sleep state EEG showed hypsarrhythmia (Fig 1). Neuroimaging revealed minor bleed in cuneus and right paraventricular white matter region. Considering the diagnosis of cryptogenic West syndrome, the baby was started with low dose adrenocorticotrophin (ACTH)

\section{Address for correspondence \\ Dr. Bikash Shrestha \\ E-mail:kalmaan@yahoo.com}

\begin{abstract}
West syndrome is the triad of mental retardation, infantile spasms and characteristic hypsarrhythmia on electroencephalograph. West syndrome usually presents in mid-infancy period. We present this as a rare presentation of West syndrome in the neonatal period.
\end{abstract}

Key words: West syndrome, Hypsarrhythmia, ACTH, Infantile spasms

therapy (20 IU/day) and phenobarbitone. ACTH has been used with good results in our centre in West syndrome. With treatment, seizures frequency reduced significantly. Sleep state EEG repeated after 14 days of ACTH showed partial subsidence of hypsarrhythmia (Fig 2). Subsequently, seizures were controlled. ACTH was continued for 4 more weeks. The baby improved neurologically. His tone had reduced and deep tendon jerks became normal. He followed light but still did not follow objects. Syrup phenobabrbitone was continued at discharge. However, at the age of 3 months, the baby had a febrile episode and after an episode of vomiting, subsequently succumbed, most probably with aspiration.

\section{Discussion}

West syndrome is one of the most catastrophic of encephalopathies of infancy and early childhood. It is characterized by its unique seizures, known as infantile spasms, which consist of spasms of flexion and extension of upper and lower limbs, with flexion of the neck, occurring in rapid successions. This was originally described by Dr William James West in his own son in 1841. The triad of infantile spasms, mental retardation and hypsarrhythmia is known as West syndrome. It is called symptomatic when the underlying etiology is obvious, cryptogenic when the underlying etiology is suspected but not localized and idiopathic when the underlying disorder is not identified. The incidence of infantile spasms has ranged from 1 in 4000-6000 live births. West syndrome is rare before 3 months and after 1 year of age with a peak at 6 months ${ }^{1}$.

\section{How to cite this article?}

Shrestha B, Kiran K, Ghuliani R. West Syndrome: How Early is Early for its Presentation? J Nepal Paediatr Soc 2013;33(3):239242. 
In approximately $40 \%$ of patients, no associated etiological factor can be clearly identified. In this case also, etiology couldn't be determined. The minor bleed shown in the MRI may have contributed, but the lesion seemed perhaps benign for it. Otherwise, various prenatal, perinatal and postnatal factors have been implicated as etiology for West syndrome. The exact pathophysiological mechanism of infantile spasms has remained a subject of extensive research. It has been proposed to occur because of disturbance of brain function due to unbalanced maturation pattern ${ }^{2}$. Others propose it to be resulted due to the involvement cortical and subcortical mechanisms. Recently, it has been proposed that perinatal stress is a cause for infantile spasms $^{3}$.

Hpysarrhythmia is considered diagnostic as well as prognostic. The subsidence of hypsarrhythmia on EEG is taken as an indication of the therapeutic response. Besides the typical hypsarrhythmia in EEG during interictal phase, a variety of ictal EEG patterns have also been identified ${ }^{4,5}$.

Our case was remarkable for its early presentation. The seizures, to begin with, did not typically fit into infantile spasms but subsequently seizures were evolving into infantile spasms. The hypsarrhythmia in sleep EEG was diagnostic. The baby also had neurodevelopmental delay. Thus, he had triad of infantile spasms, neurodevelopmental delay and hypsarrhythmia. Neuroimaging did reveal abnormality which supported the diagnosis of cryptogenic West syndrome. Response to ACTH was quite dramatic in our case. It would have been prudent to closely follow the neurodevelopment status of the child, but unfortunately, we were not able to do so.

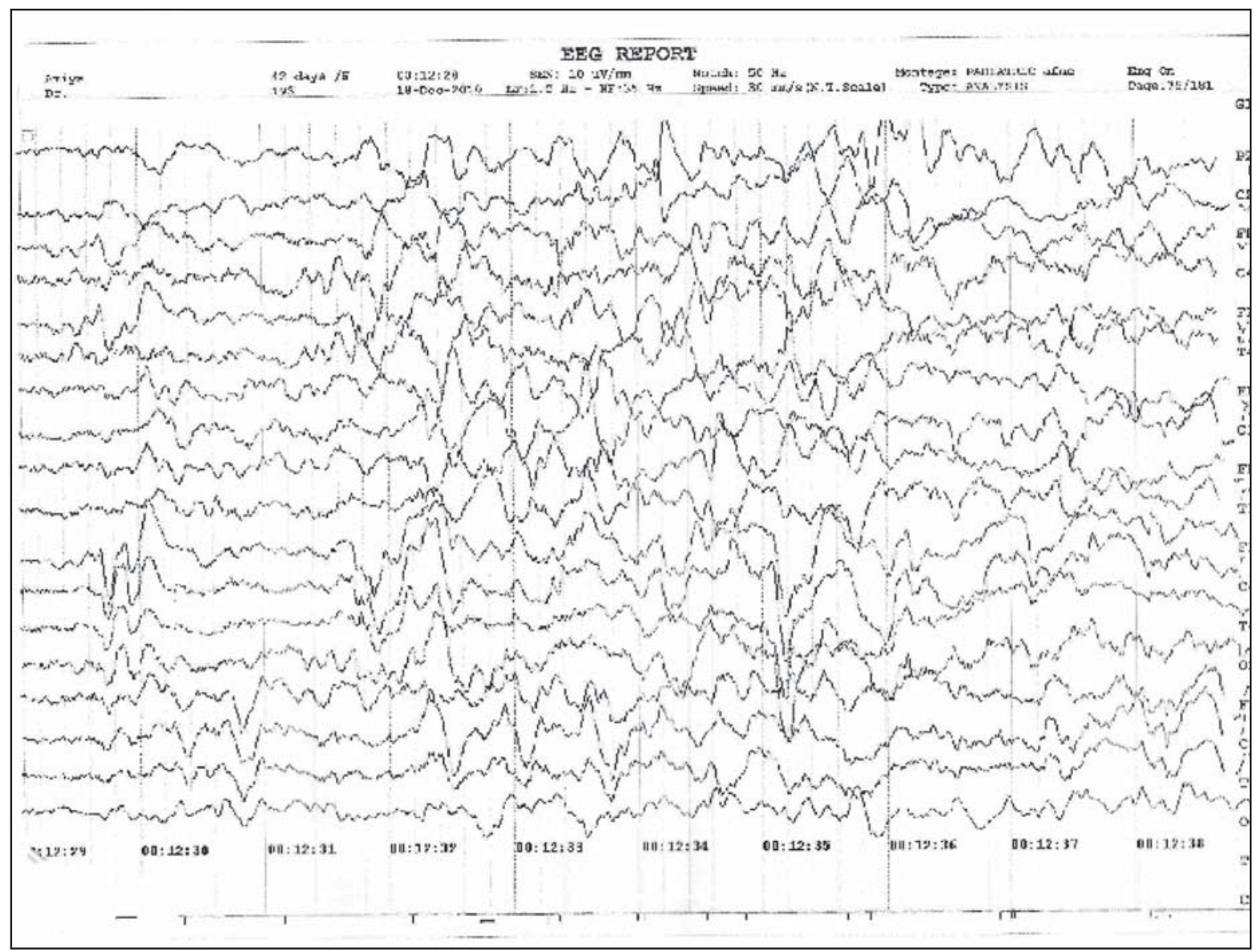

Fig 1: EEG showing hypsarrhythmia at presentation 


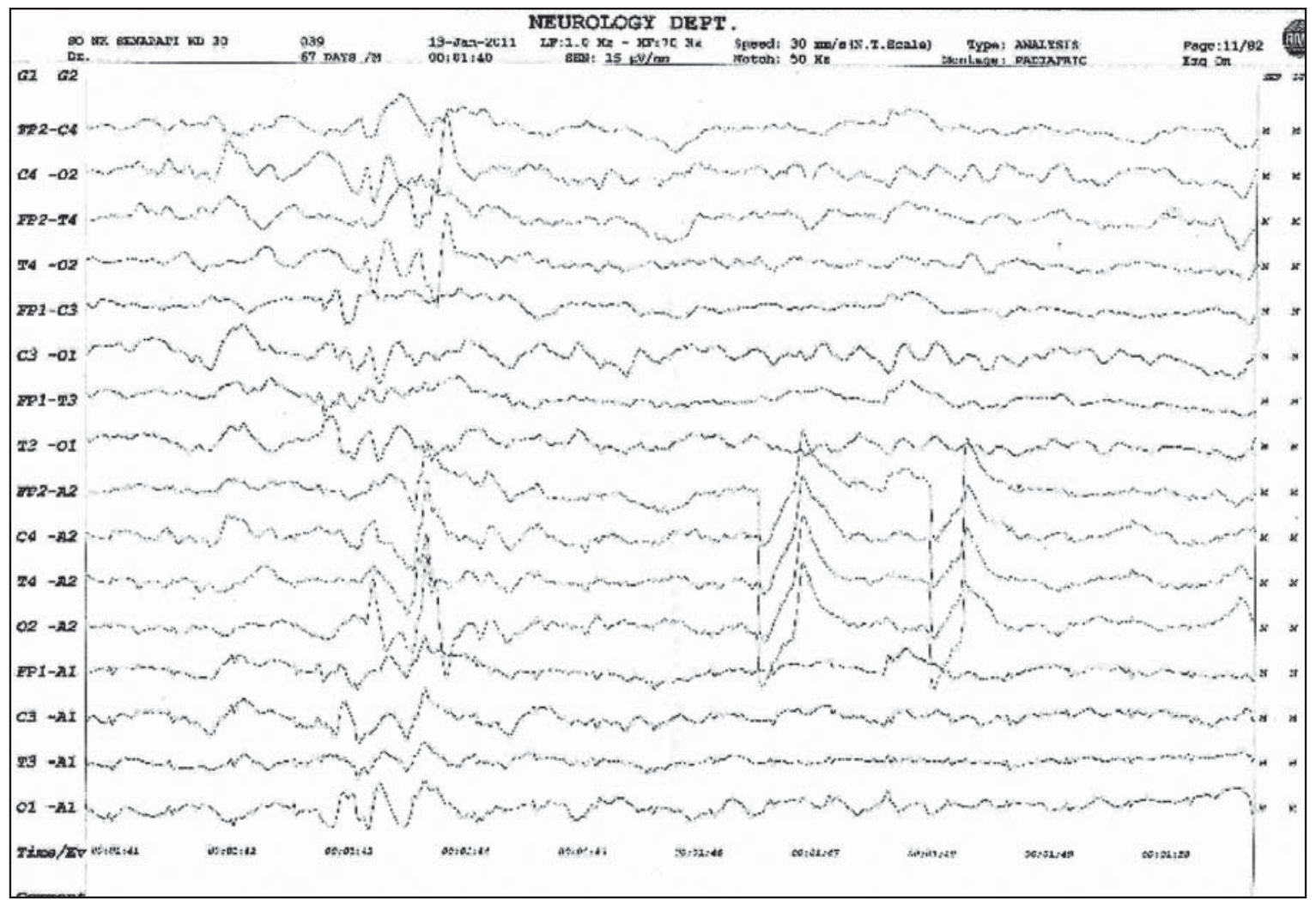

Fig 2: EEG after 2 weeks of ACTH therapy

Treatment for West syndrome consists of antiepileptic drugs as well as hormonal therapy. Vigabatrin has been the choice of treatment, especially in cases secondary to tuberous sclerosis ${ }^{6,7}$. Other choices are valproate, zonisamide, topiramate, clonazepam, nitrazepam, lamotrigine etc. The most dramatic response has been seen with hormonal therapy, especially with ACTH and prednisolone ${ }^{8}$. Newer therapeutic options are also being studied. Topiramate monotherapy was shown to be effective in a newer study from Korea ${ }^{9}$.

West syndrome has unpredictable outcome ${ }^{10}$. The disease may recover spontaneously, may remain static or progress as intractable seizures or evolve into other epileptic syndromes like Lennox Gaustat or Davert syndrome. Some may have catastrophic outcome owing to complications like in our case. Early response to ACTH therapy is considered a good prognostic marker ${ }^{11}$. The long term prognosis in terms of recovery, neurodeveleopmental outcome as well as cognitive function can't be predicted, with or without treatment. Recent studies show that outcome may be more favorable in cryptogenic ones ${ }^{12}$. Unfortunately, in our case, despite prompt improvement with ACTH, baby had a sudden demise, which was unexpected and may be implicated to the complexity of the disease itself or to other complications like aspiration. At this junction, it's impossible to conjecture whether our treatment had any effect on the course of the disease although symptomatic improvement with the treatment was definitely there with the control of seizures.

\section{Conclusion}

West syndrome is one of the most well known entities among all the infantile epileptic syndromes. Despite usual presentation in infancy, one must be aware of the possibility of such an early presentation too. This would be a guide for further research in the future into the mystic nature of West syndrome. It requires careful diagnosis, treatment, follow up, close watch upon the neurodevelopmental status and sympathetic approach towards the patient and the parents. And at the same time, the possibility of all the complications in such babies should also be looked for.

Acknowledgement: The authors would like to express their gratitude to the parents for the consent for the publication of the case.

\section{References}

1. Albert Fois. Infantile spasms: review of the literature and personal experience. Ital J Pediatr 2010;36:15

2. Guerrini R, Moro F, Kato M, Barkovich AJ, Shiihara T, McShane MA et al: Expansion of the first poly a tract of ARX causes infantile spasms and status dystonicus. Neurology 2007;69:427-33. 
3. Shi XY, Zou LP, Yang $G$ et al. Prenatal stress exposure hypothesis for infantile spasms. Med Hypotheses 2012 Mar 17. [Epub ahead of print]

4. Malik MA, Tarrar MA, Qureshi AO et al. Clinical spectrum of infantile spasm at presentation. J Coll Physicians Surg Pak. 2012;22:31-4.

5. Halevy A, Kiviti S, Goldberg-Stern H, Shuper A. [Infantile spasms and modified hypsarrhythmia] Harefuah 2011;150:373-7,417-8.

6. Elterman RD, Shields WD, Bittman RM, Torri SA, Sagar SM, Collins SD. Vigabatrin for the Treatment of Infantile Spasms: Final Report of a Randomized Trial J Child Neurol 2010;25:1340-7

7. Gaily E. Vigabatrin monotherapy for infantile spasms. Expert Rev Neurothe. 2012; 12:275-86.

8. Lux AL, Edwards SW, Hancock E, Johnson AL, Kennedy CR, Newton RW et al. The United Kingdom Infantile Spasms Study (UKISS) comparing hormone treatment with vigabatrin on developmental and epilepsy outcomes to age 14 months: a multicentre randomised trial. Lancet Neurol 2005;4:712-7.

9. Lee GM, Lee KS, Lee EH, Chung S. Short term outcomes of topiramate monotherapy as a firstline treatment in newly diagnosed West syndrome. Korean J Pediatr 2011; 54:380-4.

10. Iwatani $\mathrm{Y}$, Kagitani-Shimono $\mathrm{K}$, Tominaga $\mathrm{K}$, Okinaga T, Mohri I, Kishima $\mathrm{H}$, et al. Longterm developmental outcome in patients with West syndrome after epilepsy surgery. Brain Dev 2012 Feb13. [Epub ahead of print]

11. Riikonen R. ACTH therapy of West syndrome: Finnish views. Brain Dev 2001;23:642-6.

12. Ducal O, Plouen P, Jambaque I. Predicting favourable outcome in idiopatic West syndrome. Epilepsia 1993;34:747-56. 